\title{
Influence of the Manufacturing Parameters on the Compressive Properties of Closed Cell Aluminum Foams
}

\author{
Muhammad Ali Naeem¹, András Gábora1, Tamás Mankovits ${ }^{1 *}$ \\ ${ }^{1}$ Department of Mechanical Engineering, Faculty of Engineering, University of Debrecen, Ótemető Street 2-4, 4028 Debrecen, \\ Hungary \\ * Corresponding author, e-mail: tamas.mankovits@eng.unideb.hu
}

Received: 10 April 2020, Accepted: 21 April 2020, Published online: 29 April 2020

\begin{abstract}
The important properties of metallic foams such as good energy absorption, recyclability, noise absorption, etc. have put them at the forefront of technological development over recent years, especially for fields where the weight is a major concern. The production however, is a highly stochastic process which leads to their inhomogeneous nature. In this paper closed-cell aluminum foam specimens have been produced by direct foaming technique and investigated mechanically, following the principles of Taguchi Design of Experiments (DOE). The important compressive properties of the produced specimens such as the structural stiffness, yield strength, plateau stress and energy absorption have been measured through uniaxial compression tests and the effect of the manufacturing parameters (the temperature, the mixing speed and the amount of foaming agent added) on the energy absorption capacity of the foam is analyzed. From experiments, it was observed that the temperature is the most dominant control factor for the energy absorption capability of the foam followed by the foaming content and the mixing speed. ANOVA statistical analysis was also performed to determine the statistical significance of these parameters on the response.
\end{abstract}

Keywords

closed-cell aluminum foam, direct foaming, manufacturing parameters, energy absorption, compression test

\section{Introduction}

Metallic foams are considered to be new and novel materials which have attracted the growing attention of multiple industries in recent years due to their unique physical and mechanical properties [1]. These are complex composite structures comprising of gas filled pores surrounded by a solid metal cellular structure. The presence of the pores offers an obvious weight advantage among other favorable physical, mechanical, thermal, electrical and acoustic properties which makes them ideal for various applications, such as structural elements, automotive parts, sound and vibration absorbers or even biomedical implants [2-5].

A disadvantage in the application of metallic foams is their inhomogeneous nature which results from the stochastic nature of the production process. The problem is that the molten foam is not thermodynamically stable, and the conditions are continuously changing during the foaming process [1]. The principle of foaming of metals is however quite old and most of the methods used today have been already introduced in the 1950s. A history of the innovation and the technological challenges for the manufacturing of metallic foams has been presented in [6] which traces back the earliest mention metallic foams to the mid-1920s. Since then, various studies have been carried out to predict the properties of the produced aluminum foams. These studies and developments have made possible the application of metallic foams as a lightweight structure with high specific compression strength and good energy absorption characteristics. This is especially true in the case of the automotive and aerospace industries where the weight is highly relevant [7].

Metallic foams on the basis of cellular structure can be classified as either open-cell foams or closed-cell foams (special class: Metal Matrix Syntactic Foams [8]). These foams can be produced by various method using various materials. However, these methods can be classified into nine distinct process routes which are presented in [9]. Most of the presented techniques have been established commercially and all metallic foams these days are made by one of the nine process or a variant of them.

Among metallic foams, aluminum foams are the most widely manufactured material because they provide a rare 
combination of properties such as low density, blast amelioration, high energy absorption during compressive static and dynamic loading, flame resistance and sound absorption [10]. A review of the process parameters and foaming agents used in the manufacturing methods of aluminum foam has been presented in [11]. It also discusses the benefits and concerns associated with their uses.

The sample preparation procedures and tests to determine the mechanical properties of the foam structure have been presented in [12] keeping into consideration the specific application of these tests to study cellular materials. This need for characterization of a metallic foam is of utmost importance either to obtain the mechanical or physical properties of the cellular material under investigation or to perform a technical characterization of the part containing the cellular material.

Numerous researches have been carried out to study the mechanical properties of different type of metallic foams. These studies and their results can be found in the literature. The compressive properties of open cell metallic foam structures and the tensile properties of open cell aluminum foam sandwich where investigated in [13, 14], while the fracture behavior of closed cell metal foams was investigated in [15]. Studies are also available on the special class of closed cell foams referred to as Metal Matrix Syntactic foams. The compressive response behavior of them has been studied in [8, 16-18].

The stochastic nature of the production process has a huge effect on the properties of the produced metal foams. There are a number of factors which determine the behavior of the material. The effect of the human factor on the quality control of closed cell metal foams product by direct foaming was analyzed in [19], while the effect of various manufacturing parameters has been investigated and the techniques for optimizing the process have been presented in [1, 20, 21].

In the professional literature, there are many methods available for the optimization of an engineering process. The Taguchi method is one of them. It employs orthogonal arrays to optimize the process and to improve the quality of the manufactured products by analyzing the whole parameter space through only a small number of experiments. The method has already been applied in different industrial processes and operations such as turning [22], facing [23], milling [24] and casting [25].

In this research, closed-cell aluminum foam specimens have been manufactured following the principles of Design of Experiments (DOE). The important compressive properties of the produced specimens have been measured by performing compressions tests and the effect of the manufacturing parameters (the temperature, the mixing speed, and the amount of foaming agent added) on the energy absorption capacity of the foam has been analyzed. ANOVA statistical analysis has also been performed to determine the statistical significance of these parameters on the response.

\section{Materials and methods}

The primary raw material used for our study was the Duralcan F3S.20S Metal Matrix Composite (MMC) provided by Rio Tinto Ltd, which contains silicon carbide ( $\mathrm{SiC}$ ) particles. The chemical composition of the matrix material is determined with EDX analysis and listed in Table 1 [26]. The SiC particles offer sufficient viscosity modification for the stabilization of the melt and eliminate the need for introducing additional stabilizing particles. Furthermore, the foaming agent used was titanium hydride $\left(\mathrm{TiH}_{2}\right)$ with particle size $3 \mu \mathrm{m}$ and provided by Alfa Aesar Ltd.

The specimens required for further examinations were produced by direct foaming method under normal atmospheric conditions. The foaming procedure is carried out in a pre-heated furnace (Goldbrunn 3000) at different temperatures. The process starts off with adding preweighed metal composite billets, which are cast from the original block, into the furnace. Once molten, the foaming agent $\left(\mathrm{TiH}_{2}\right)$ is inserted into the melt and the whole mixture is stirred for about 15 seconds using a mixing head attached to variable speed drills (Metabo SBE750 \& Makita DDF458Z). The stirring time has been kept constant in all the production runs and based on our experience is enough to provide sufficient mixing. Furthermore, the mixing head made from 1.4301 steel does not alter the chemical composition of the melt.

As the mixing process takes place, the foaming agent decomposes into $\mathrm{Ti}$ and gaseous $\mathrm{H}_{2}$. The large amount of rapidly created hydrogen gas causes the metal melt to expand and the stirring system is withdrawn. Once the foaming process stops, the melt is water cooled down to below its melting point, to stabilize and solidify the foam before the bubbles collapse, resulting in the formation of a closed-cell aluminum foam structure.

Table 1 Chemical composition of Duralcan F3S.20S MMC

\begin{tabular}{lccccc}
\hline \multirow{2}{*}{ Matrix } & \multicolumn{5}{c}{ Composition (wt\%) } \\
& $\mathrm{Al}$ & $\mathrm{Si}$ & $\mathrm{Mg}$ & $\mathrm{SiC}$ & other \\
\hline F3S.20S MMC & 69.26 & 9.21 & 0.53 & 20.8 & 0.2 \\
\hline
\end{tabular}


There are numerous parameters that can influence the compressive capability of the produced metallic foams. The experimental process parameters and their respective levels included in the scope of this study after careful consideration are shown in Table 2. These process parameters are namely the temperature, the speed and the weight fraction of the foaming agent added which can all be controlled easily, effectively and economically. Furthermore, the levels are chosen based on the literature available related to the topic.

The standard approach for the DOE requires us to use the full factorial method when there are two or more factors, each with a set of their own discrete levels. Such an experimental design takes into account all the possible combinations of all those levels which have been selected for the process parameters and allows us to study the effect of each factor on the response variable. This approach however can be quite laborious and complicated when a high number of factors are being observed. The Taguchi method helps us to overcome the problem by enabling us to study the complete parameter space by using just a fraction of the total number of experiments that are required for a full factorial analysis. It introduces a loss function to measure the quality characteristics (namely; smaller-the-better, larger-the-better and nominal-the-best) which deviate from the desired target value and transforms it into a signal-to-noise ratio $(\mathrm{S} / \mathrm{N})$. The analysis of the results allows us to determine the optimal process parameter settings for the response, and estimate the percentage of contribution of each individual factor towards the response.

A L9 orthogonal array as shown in Table 3 was selected to conduct our experimental runs. It reduces our total experimental runs to just a mere 9 runs as opposed to the total of 27 required for a full factorial analysis.

Furthermore, each experimental run was repeated 5 times to account for the variations that may occur in the process as a result of any noise factors, resulting in a total of 45 specimens.

After cooling, the foamed specimens were cut into $30 \mathrm{~mm} \times 30 \mathrm{~mm} \times 30 \mathrm{~mm}$ cubes (as shown in Fig. 1) using a Struers Labotom-3 cutting machine following

Table 2 Experimental factors and levels

\begin{tabular}{lccc}
\hline Factors & Level 1 & Level 2 & Level 3 \\
\hline Temperature $\left({ }^{\circ} \mathrm{C}\right)$ & 750 & 800 & 850 \\
Mixing speed $(\mathrm{rpm})$ & 1000 & 2000 & 1500 \\
$\mathrm{TiH}_{2}$ fraction $(\mathrm{wt} \%)$ & 1.0 & 1.5 & 2.0 \\
\hline
\end{tabular}

Table 3 Taguchi L9 orthogonal array

\begin{tabular}{lccc}
\hline $\begin{array}{l}\text { Production } \\
\text { Run no. }\end{array}$ & Temperature & $\begin{array}{c}\text { Parameter Level } \\
\text { Mixing Speed }\end{array}$ & $\mathrm{TiH}_{2}$ fraction \\
\hline 1. & 1 & 1 & 1 \\
2. & 1 & 2 & 2 \\
3. & 1 & 3 & 3 \\
4. & 2 & 1 & 2 \\
5. & 2 & 2 & 3 \\
6. & 2 & 3 & 1 \\
7. & 3 & 1 & 3 \\
8. & 3 & 2 & 1 \\
9. & 3 & 3 & 2 \\
\hline
\end{tabular}

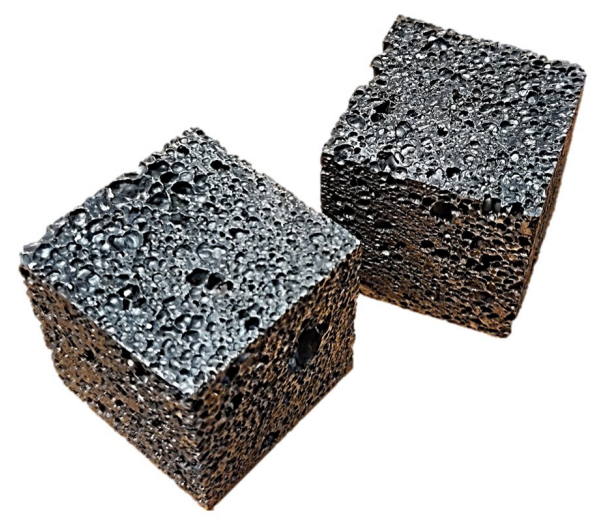

Fig. $130 \mathrm{~mm} \times 30 \mathrm{~mm} \times 30 \mathrm{~mm}$ aluminum foam specimens cut according to the ISO 13314 standard

the ISO 13314 standard [27]. According to the standard, all spatial dimensions of the specimen have to be at least 10 times the average cell size. This size was measured by performing a macroscopic quantitative image analyses on the cross-sectional structure of the foamed specimens.

The cut samples were subjected to uniaxial compression tests at room temperature using an INSTRON 8801 type universal testing machine as shown in Fig. 2.

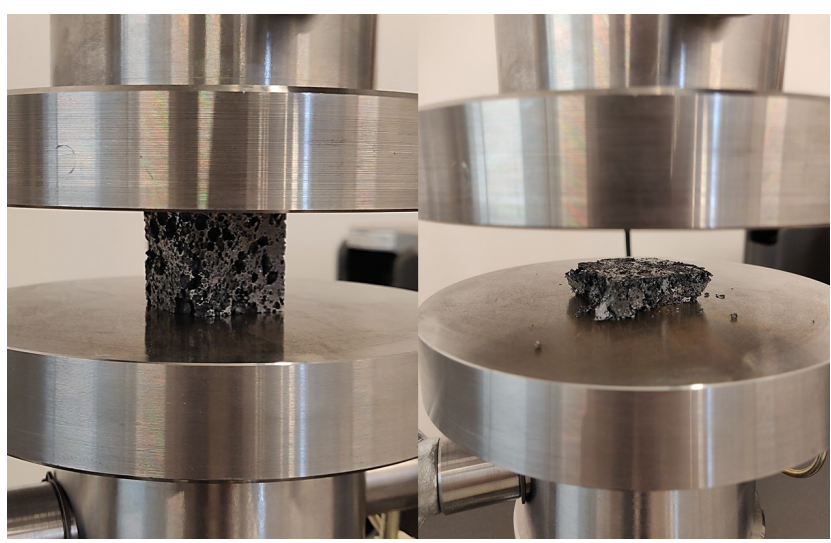

Fig. 2 Aluminum foam specimen before and after the compression test 
The deformation during the tests was performed under quasi-static conditions at a constant rate of $8.7 \mathrm{~mm} / \mathrm{min}$ and the compressive stress-strain curves for each sample were recorded using the WaveMatrix 2 console software.

\section{Results and discussion}

The data obtained from the uniaxial compression tests has been converted into an average compressive stress-strain curve for all 9 experimental runs as shown in Fig. 3.

The average porosity and the important compressive properties of the metallic foam specimens such as the structural stiffness, yield strength (0.2\% strain offset), plateau stress (average stress between $20 \%$ and $40 \%$ compressive strain) and energy absorption (corresponding to a value of $40 \%$ deformation) are listed in Table 4. These were calculated from the average compressive stress-strain curves following the ISO 13314 standard [27].

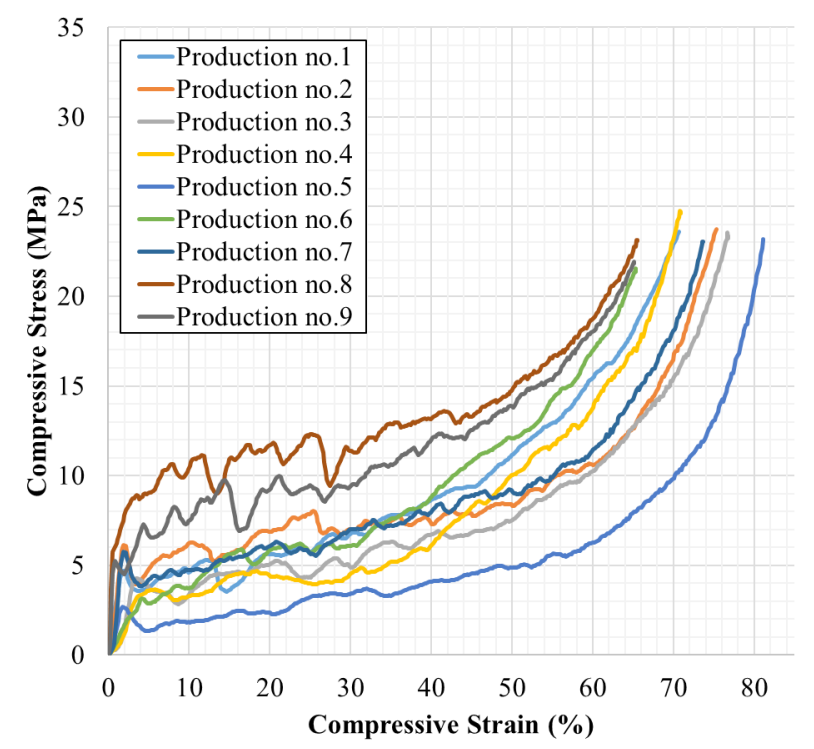

Fig. 3 Average compressive stress-strain curves for the experimental runs
Taguchi analysis was performed on the data obtained for the energy absorption capability of the foams using Minitab statistical software. Since the energy absorption capability of the material should be high as possible, the larger-the-better performance characteristic was selected for the analysis. The obtained main effects plot for Means and S/N ratios are shown in Fig. 4 and Fig. 5 respectively.

Fig. 4 and Fig. 5 indicate that the compressive energy absorption response of the metallic foams is maximum at a process parameter setting of; temperature $\left(850{ }^{\circ} \mathrm{C}\right)$, mixing speed (2000 rpm) and $\mathrm{TiH}_{2}$ content $(1.0 \mathrm{wt} \%$ ) while the $\mathrm{S} / \mathrm{N}$ ratio for the response is maximum (system is less susceptible to variation due to noise factors) at a process parameter setting of; temperature $\left(850{ }^{\circ} \mathrm{C}\right)$, mixing speed (1500 rpm) and $\mathrm{TiH}_{2}$ content (1.0 wt\%). It can however be seen that the mixing speed has a higher influence on the mean of the energy absorbed as compared to the influence on the $\mathrm{S} / \mathrm{N}$ ratio. Therefore, setting the mixing speed to $2000 \mathrm{rpm}$ will increase the energy absorption response of the produced samples without significantly effecting the $\mathrm{S} / \mathrm{N}$ ratio of the process. Hence the optimal setting for mixing speed should be $2000 \mathrm{rpm}$.

A confirmation experiment is not required in our case since the optimal process parameter settings determined already correspond to experimental run no. 8 given in Table 3. Looking at the table it is evident that these settings give us the maximum compressive energy absorption response for the aluminum foam specimens.

The obtained response tables for Means and $\mathrm{S} / \mathrm{N}$ ratios are also shown in Table 5 and Table 6 respectively. The tables indicate the average of the response characteristic at each level of the control factor. By looking at the calculated delta values (difference between the highest and lowest average response values for each factor), we can see that the most dominant factor effecting

Table 4 Average porosity and compressive properties of aluminum foam specimens

\begin{tabular}{|c|c|c|c|c|c|}
\hline $\begin{array}{l}\text { Production } \\
\text { Run no. }\end{array}$ & $\begin{array}{c}\text { Porosity } \\
(\%)\end{array}$ & $\begin{array}{c}\text { Structural Stiffness } \\
S_{s}(\mathrm{MPa})\end{array}$ & $\begin{array}{l}\text { Yield Strength } \\
\sigma_{y 0.2 \%}(\mathrm{MPa})\end{array}$ & $\begin{array}{c}\text { Plateau Stress } \\
\sigma_{p l 20-40}(\mathrm{MPa})\end{array}$ & $\begin{array}{c}\text { Energy Absorption } \\
W_{40 \%}\left(\mathrm{MJ} / \mathrm{m}^{3}\right)\end{array}$ \\
\hline 1. & 85.8 & 312.5 & 4.6 & 6.8 & 2.2 \\
\hline 2. & 86.4 & 425.8 & 6.1 & 7.3 & 2.6 \\
\hline 3. & 88.2 & 246.9 & 4.2 & 5.4 & 1.8 \\
\hline 4. & 85.1 & 155.3 & 3.1 & 4.7 & 1.6 \\
\hline 5. & 90 & 219.2 & 2.7 & 3.3 & 1.1 \\
\hline 6. & 83.1 & 92.4 & 2.2 & 6.7 & 2.1 \\
\hline 7. & 86.8 & 546.5 & 5.7 & 6.7 & 2.3 \\
\hline 8. & 84.7 & 1565.7 & 5.9 & 11.8 & 4.4 \\
\hline 9. & 81.4 & 1157.3 & 4.9 & 10 & 3.5 \\
\hline
\end{tabular}




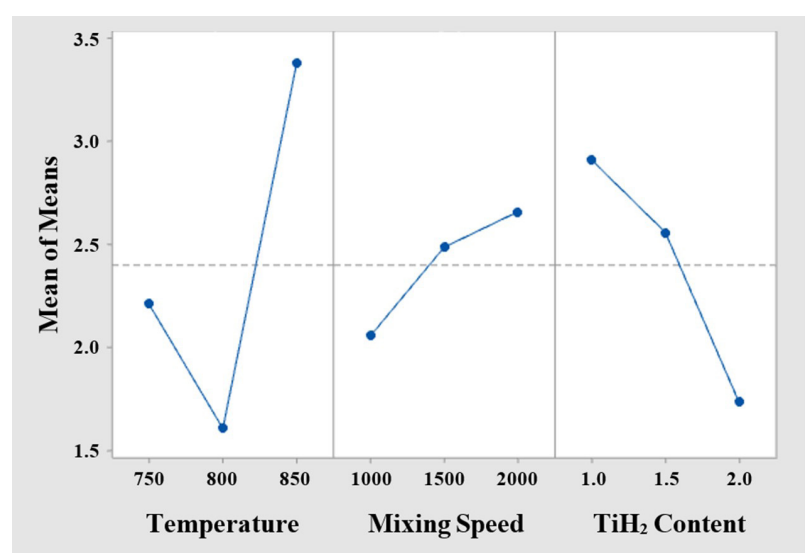

Fig. 4 Main effects plot for means

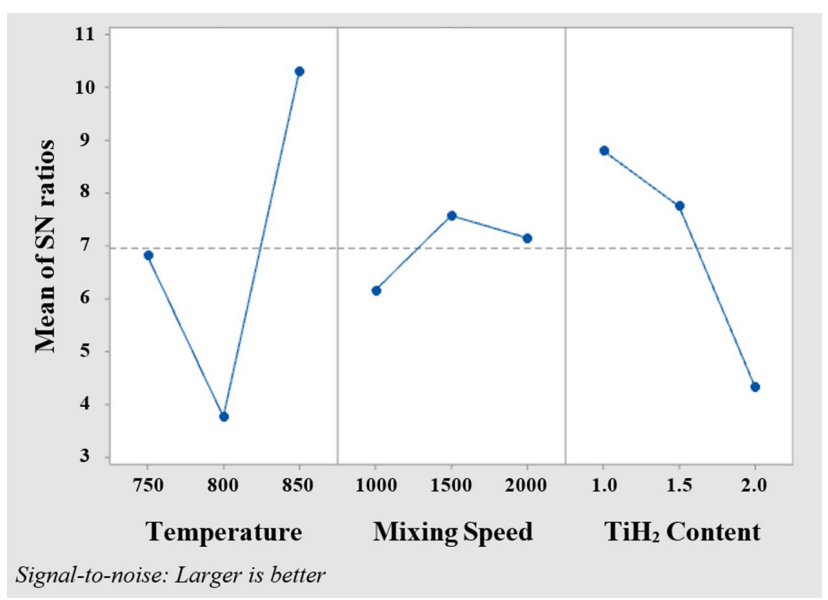

Fig. 5 Main effects plot for $\mathrm{S} / \mathrm{N}$ ratios

Table 5 Response table for means

\begin{tabular}{lccc}
\hline Level & Temperature & Mixing Speed & $\mathrm{TiH}_{2}$ Content \\
\hline 1 & 2.211 & 2.056 & 2.910 \\
2 & 1.606 & 2.485 & 2.557 \\
3 & 3.381 & 2.657 & 1.730 \\
Delta & 1.775 & 0.601 & 1.180 \\
Rank & 1 & 3 & 2 \\
\hline
\end{tabular}

Table 6 Response table for $\mathrm{S} / \mathrm{N}$ ratios

\begin{tabular}{lccc}
\hline Level & Temperature & Mixing Speed & $\mathrm{TiH}_{2}$ Content \\
\hline 1 & 6.809 & 6.154 & 8.793 \\
2 & 3.763 & 7.565 & 7.741 \\
3 & 10.291 & 7.143 & 4.328 \\
Delta & 6.528 & 1.411 & 4.465 \\
Rank & 1 & 3 & 2 \\
\hline
\end{tabular}

both the means and $\mathrm{S} / \mathrm{N}$ ratios of the response is the melt temperature followed by the amount of $\mathrm{TiH}_{2}$ content added and the mixing speed.

Furthermore, to determine the significance of the correlation between each control factor and the compressive response of the metallic foam specimens, ANOVA (analysis of variance) was performed. The results of the analysis are shown in Table 7.

Looking at the $p$-values (probability that measures whether or not the association between the control factors and the response is statistically significant or not) in Table 6, it can be seen that the effect of temperature on the response is significant at a $95 \%$ confidence level.

Fig. 6 shows the residual plots for energy absorbed obtained as a result of performing ANOVA. The plots show the fitted values that are the theoretical values and residuals (i.e., the difference theoretical values and the experimental values). They also show the variation in the residuals in all experiments as well as the upper and lower range fitted values from zero residual. It can be observed that the residuals generally fall on a straight line which imply that there is a normal distribution of the errors. It may therefore be concluded that all the values lie within the control range, that there is no apparent trend, and that the residual analysis does not represent any inadequacy of the model.

From Table 4 it can be seen that other properties (structural stiffness, yield strength, plateau stress) with higher values can be obtained with applying higher operating temperature, higher mixing speed and less $\mathrm{TiH}_{2}$ fraction.

The Taguchi method can be applied to find the optimal process parameters for any of the properties listed in Table 4, however, these optimal process settings might

Table 7 ANOVA results for energy absorption

\begin{tabular}{lccccc}
\hline Source & DF & Adj SS & Adj MS & $F$-Value & $P$-Value \\
\hline Temperature & 2 & 4.8872 & 2.4436 & 25.59 & 0.038 \\
Mixing Speed & 2 & 0.5747 & 0.2873 & 3.01 & 0.249 \\
TiH $_{2}$ Content & 2 & 2.1997 & 1.0998 & 11.52 & 0.080 \\
Error & 2 & 0.1910 & 0.0955 & & \\
Total & 8 & 7.8526 & & & \\
\hline
\end{tabular}

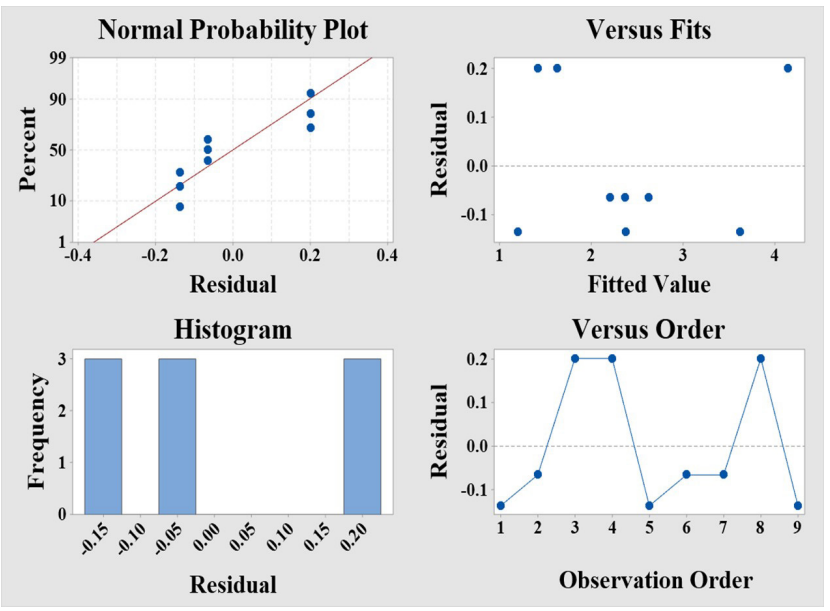

Fig. 6 Residual plots for energy absorbed 
differ for each of characteristics taken into consideration. The reason being that the Taguchi method needs to be coupled with additional multi-objective optimization techniques to find a solution to a multi-objective problem. One such technique has been presented in [1] where multi-objective optimization for minimizing the relative density and maximizing the energy absorption of metallic foams has been carried out by combining the Taguchi method with regression analysis. This field of combining additional algorithms and techniques with the Taguchi methodology to find multi-objective optimization solutions for multiple foam characteristics represents a potential are for further research.

\section{Conclusion}

In this paper, closed-cell aluminum foam specimens were produced by direct foaming technique following the principles of Taguchi DOE. A L9 orthogonal array resulting

\section{References}

[1] Surace, R., Bruno, S., De Filippis, L. A. C., Ludovico, A. D. "Multi-objective Optimization of Aluminium Foam Manufacturing Parameters", International Journal of Simulation Modelling, 8(2), pp. 81-89, 2009.

https://doi.org/10.2507/IJSIMM08(2)2.121

[2] Aboraia, M., Sharkawi, R., Doheim, M. A. "Production of Aluminium Foam and the Effect of Calcium Carbonate as a Foaming Agent", Journal of Engineering Sciences, Assiut University, 39(2), pp. 441-451, 2011.

[3] Djebbar, N., Serier, B., Bouiadjra, B. B., Benbarek, S., Drai, A. "Analysis of the effect of load direction on the stress distribution in dental implant", Materials \& Design, 31(4), pp. 2097-2101, 2010. https://doi.org/10.1016/j.matdes.2009.10.042

[4] Vendra, L., Rabiei, A. "Evaluation of modulus of elasticity of composite metal foams by experimental and numerical techniques", Materials Science and Engineering A, 527(7-8), pp. 1784-1790, 2010.

https://doi.org/10.1016/j.msea.2009.11.004

[5] Kashef, S., Asgari, A., Hilditch, T. B., Yan, W., Goel, V. K., Hodgson, P. D. "Fracture toughness of titanium foams for medical applications", Materials Science and Engineering: A, 527(29-30), pp. 7689-7693, 2010.

https://doi.org/10.1016/j.msea.2010.08.044

[6] Banhart, J. "Light-Metal Foams - History of Innovation and Technological Challenges", Advanced Engineering Materials, 15(3), pp. 82-111, 2013.

https://doi.org/10.1002/adem.201200217

[7] Banhart, J. "Manufacture, characterisation and application of cellular metals and metal foams", Progress in Materials Science, 46(6), pp. 559-632, 2001. https://doi.org/10.1016/S0079-6425(00)00002-5

[8] Orbulov, I. N., Ginsztler, J. "Compressive Behaviour of Metal Matrix Syntactic Foams", Acta Polytechnica Hungarica, 9(2), pp. 43-56, 2012. in 9 production runs was chosen to conduct the experiments by varying three process parameters; the temperature, the mixing speed, and the amount of foaming agent added. Uniaxial compression tests were performed on the produced foam specimens to measure the average structural stiffness, yield strength, plateau stress and energy absorption capability of the samples produced through each production run. Furthermore, the effect and significance of the manufacturing parameters on the energy absorption capability was analyzed using the Taguchi method and by performing ANOVA statistical analysis through the MiniTab software. The analysis indicates that the temperature is the most dominant control factor for the energy absorption capability of the foam followed by the foaming content and the mixing speed. Also, the effect of the temperature is statistically significant at a $95 \%$ confidence level.

[9] Ashby, M. F., Evans, A. G., Fleck, N. A., Gibson, L. J., Hutchinson, J. W., Wadley, H. N. G. "Metal Foams: A Design Guide", Butterworth-Heinemann, Boston, USA, 2000.

[10] Gokhale, A. A., Kumar, N. V. R., Sudhakar, B., Sahu, S. N., Basumatary, H., Dhara, S. "Cellular Metals and Ceramics for Defence Applications", Defence Science Journal, 61(6), pp. 567-575, 2011. https://doi.org/10.14429/dsj.61.640

[11] Vikas, K. S. R., Ram, N. R., Reddy, C. K., Raju, V. V. S. "Process Parameters and Foaming Agents Used in Manufacturing of Aluminium metallic foams: A Review", International Journal of Scientific Engineering and Technology, 4(11), pp. 505-510, 2015. https://doi.org/10.17950/ijset/v4s11/1101

[12] Stręk, A. M. "Methodology for Experimental Investigations of Metal Foams and Their Mechanical Properties", Mechanics and Control, 31(2), pp. 90-96, 2012.

https://doi.org/10.7494/mech.2012.31.2.90

[13] Devivier, C., Tagliaferri, V., Trovalusci, F., Ucciardello, N. "Mechanical characterization of open cell aluminium foams reinforced by nickel electro-deposition", Materials \& Design, 86, pp. 272-278, 2015.

https://doi.org/10.1016/j.matdes.2015.07.078

[14] Ibrahim, N. A., Al Hazza, M. H. F., Adesta, E. Y. T., Sidek, A. B. A., Endut, N. A. "A study of tensile test on open-cell aluminum foam sandwich", IOP Conference Series: Materials Science and Engineering, 290, Article number: 012083, 2018. https://doi.org/10.1088/1757-899X/290/1/012083

[15] Onck, P. R., Van Merkerk, R., Raaijmakers, A., De Hosson, J. T. M. "Fracture of open- and closed-cell metal foams", Journal of Materials Science, 40(22), pp. 5821-5828, 2005. https://doi.org/10.1007/s10853-005-4996-7

[16] Orbulov, I. N. "Compressive properties of aluminium matrix syntactic foams", Materials Science and Engineering: A, 555, pp. 52-56, 2012.

https://doi.org/10.1016/j.msea.2012.06.032 
[17] Orbulov, I. N., Májlinger, K. "Description of the compressive response of metal matrix syntactic foams", Materials \& Design, 49, pp. 1-9, 2013.

https://doi.org/10.1016/j.matdes.2013.02.007

[18] Szlancsik, A., Katona, B., Bobor, K., Májlinger, K., Orbulov, I. N. "Compressive behaviour of aluminium matrix syntactic foams reinforced by iron hollow spheres", Materials \& Design, 83, pp. 230-237, 2015 .

https://doi.org/10.1016/j.matdes.2015.06.011

[19] Gábora, A., Mankovits, T. "Quality control of closed-cell metal foam produced by direct foaming", IOP Conference Series: Materials Science and Engineering, 659, Article number: 012037, 2019. https://doi.org/10.1088/1757-899X/659/1/012037

[20] Surace, R., De Filippis, L. A. C., Ludovico, A. D., Boghetich, G. "Experimental analysis of the effect of control factors on aluminium foam produced by powder metallurgy", Estonian Journal of Engineering, 13(2), pp. 156-167, 2007.

[21] Surace, R., De Filippis, L. A. C., Ludovico, A. D., Boghetich, G. "Application of Taguchi method for the multi-objective optimization of aluminium foam manufacturing parameters", International Journal of Material Forming, 3(1), pp. 1-5, 2010. https://doi.org/10.1007/s12289-009-0409-9

[22] Ranganath, M. S., Vipin, Mishra, R. S., Prateek, Nikhil "Optimization of Surface Roughness in CNC Turning of Aluminium 6061 Using Taguchi Techniques", International Journal of Modern Engineering Research (IJMER), 5(5), pp. 42-50, 2015. [online] Available at: http://www.ijmer.com/papers/Vol5_Issue5/ Version-1/F0505_01-4250.pdf [Accessed: 03 April 2020]
[23] Athreya, S., Venkatesh, Y. D. "Application Of Taguchi Method For Optimization Of Process Parameters In Improving The Surface Roughness Of Lathe Facing Operation", International Refereed Journal of Engineering and Science (IRJES), 1(3), pp. 13-19, 2012.

[24] Ghani, J. A., Choudhury, I. A., Hassan, H. H. "Application of Taguchi method in the optimization of end milling parameters", Journal of Materials Processing Technology, 145(1), pp. 84-92, 2004. https://doi.org/10.1016/S0924-0136(03)00865-3

[25] Vijian, P., Arunachalam, V. P. "Optimization of squeeze cast parameters of LM6 aluminium alloy for surface roughness using Taguchi method", Journal of Materials Processing Technology, 180(1-3), pp. 161-166, 2006. https://doi.org/10.1016/j.jmatprotec.2006.05.016

[26] Mankovits, T., Budai, I., Balogh, G., Gábora, A., Kozma, I., Varga, T., Manó, S., Kocsis, I. "Structural analysis and its statistical evaluation of a closed-cell metal foam", International Review of Applied Sciences and Engineering, 5(2), pp. 135-143, 2014. https://doi.org/10.1556/IRASE.5.2014.2.5

[27] International Organization for Standardization "ISO 13314: 2011 Mechanical testing of metals - Ductility testing - Compression test for porous and cellular metals", ISO, Geneva, Switzerland, 2011. 